\title{
Increasing the Tracks Efficiency by Using Energy-Saving Oils in Transmission and Engine
}

\author{
Anatoliy Ponomarenko ${ }^{1}$, Mikhail Boiko ${ }^{2}$, Mikhail Lyashenko ${ }^{3}$, and Vitaly Dudnik ${ }^{4, *}$ \\ ${ }^{1}$ Southern Federal University, 344006, Bolshaya Sadovaya Street 105/42, Rostov-on-Don, Russia \\ ${ }^{2}$ Rostov State Transport University, 344038, Rostovskogo Strelkovogo Polka Narodnogo \\ Opolcheniya Square 2, Rostov-on-Don, Russia \\ ${ }^{3}$ Volgograd State Technical University, 400005, Lenin avenue 28, Volgograd, Russia \\ ${ }^{4}$ Don State Technical University, 344000, Gagarin square 1, Rostov-on-Don, Russia
}

\begin{abstract}
A method for improving the efficiency of construction machinery and vehicles by using the energy-saving engine and transmission oils is proposed. Developed additives give to oils the energysaving properties. The results of oils tests in engines and transmissions of trucks are given. It is shown the modified oils using reduces the fuel by $7.2 \%-8.3 \%$, the efficiency of the transmission increases to $12 \%$.
\end{abstract}

\section{Introduction}

The operational transport costs depend from the effectiveness of vehicles. Thus, the increasing of performance of the trucks leads to a reduction in the total transport costs. It is known the largest energy losses of engine vehicles occur when the energy of the fuel is converted into mechanical energy [1]. Reduction of these losses is possible with the using of energy-saving lubricants. We have developed the following additive packages: PMM for engine oils based on dicarboxylic acid ester and complex molybdenum compound; PMT - for gear oil based on dicarboxylic acid ester and complex copper compound; nanoPMT for gear oil based on dicarboxylic acid ester and copper nanoparticles. These additives form a tribopolymer film on friction surfaces, which reduces friction losses [2-5]. The effectiveness of the energy-saving lubricants using was confirmed during the tests on trucks of various carrying capacity.

\section{Materials and methods}

Tests were carried out on trucks GAZ 3302 , ZIL-130, KAMAZ 5511, GAZ-66, ZIL-131, Hyundai Porter.

Oils samples were tested:

- engine oil for gasoline engines SAE 10W40 (M5z / 14G) modified with 2\% PMM additive;

- engine oil for diesel engines Rosneft SAE 30 (M-10G2CS) modified 2\% PMM additive;

\footnotetext{
* Corresponding author: vvdudnik@mail.ru
} 
- transmission mineral oil Gazpromneft SAE 80 W90 (TSp-15k) modified with 2\% PMT additive;

- transmission mineral oil Gazpromneft SAE 80 W90 (TSp-15k) modified with 2\% nanoPMT additive.

The measurements were carried out at the following intervals: $50-100 \mathrm{~km} ; 150-250 \mathrm{~km}$; $300-400 \mathrm{~km} ; 450-550 \mathrm{~km} ; 900-1100 \mathrm{~km} ; 1500-1700 \mathrm{~km} ; 2000-2500 \mathrm{~km}$. All trucks were operated in a mixed city / intercity cycle.

Measurements were carried out at the idle rotational speed of the vehicle engine, then at $1000 \mathrm{rpm}$ and $2000 \mathrm{rpm}$. The next parameters are registered: the content of carbon monoxide $(\mathrm{CO})$ and hydrocarbons $(\mathrm{CH})$ in the exhaust gases; level of acoustic emission during the truck working; fuel consumption; temperature of the internal combustion engine.

Refinement of the data obtained during the simulation of the transmission work was carried out at the bench with the full-sized driving back axle of the truck. The bench was included the KAMAZ test back axle, Dynapack DP43 dynamometer which used as a loading device. The drive was carried out with the asynchronous electric motor AIR180s2, which was connected to the flange of the axle by the standard cardan shaft of the truck. The motor was controlled by the Altivar 71 frequency converter $(0.1 \mathrm{~Hz}$ step in the range 0 $1600 \mathrm{~Hz}$ ). The run of the KAMAZ truck axle was about $3 / 4$ of the resource.

The driving axle of the KAMAZ truck contained a two-stage conical-cylindrical main gear, a simple conical differential with four satellites, axle shafts, a locked interaxle differential. Rather large number of bearing assemblies and friction surfaces are presence at this assembly.

The thermal characteristics of the axle were estimated by infrared pyrometer (measurement limits -50 to $330{ }^{\circ} \mathrm{C}$, error $\pm 1.5 \%\left(1.5^{\circ} \mathrm{C}\right.$ ), resolution $0.1^{\circ} \mathrm{C}$ ). During the tests, temperature measurements were made at the checking points of the axle.

The following test mode was chosen:

- the constant engine speed, set by the frequency converter $n=1200 \pm 10 \mathrm{rpm}$,

- the constant load at the output links of the back axle (appropriate power of 10 or $13 \mathrm{~kW}$ ), set by the Dynapack dynamometer.

The effect of the energy-saving additive should appear in the changing of the mechanical part efficiency of the axle. Thus during the axle tests with the modified oil, the power performance should change at the input shaft (due to the change in the torque).

The RPM of the engine shaft was measured by a contactless optical sensor BC-401 (speed range $0-20000 \mathrm{rpm}$, sensitivity at $\mathrm{E}=1 \mathrm{~mW} / \mathrm{K}-750 \mathrm{mV}$ ). An optical mark was installed on the shaft surface to measure the rotational speed. Analog-to-digital conversion and signal transmission from vibration and optical sensors to a computer was performed by a multichannel spectrum analyzer ZET 017-U8.

Torque on the motor shaft was measured by four strain gages TKF Ol-2-200, fixed on the shaft by bridged scheme. Strain gauge bridge was calibrated before the experiment. Analog-to-digital conversion of the signal from the strain gauge bridge were performed by module ZET 7111. The transmission through the radio channel was done by intelligent interface $7172 \mathrm{~S}$ ZET - ZET $7172 \mathrm{M}$. The conversion of the received radio signal for transmission via the USB interface to the computer was performed by intelligent USBCAN interface converter ZET 7174. Visualization of measurement results and dialogue with the operator was implemented in the program developed in the environment of measurement automation Zetview Scada.

Tests with unmodified oil were carried out until the axle reaches the steady-state nominal temperature at some point. It was assumed that the temperature is considered steady-state if its change within an hour does not exceed $0.5^{\circ} \mathrm{C}$ (temperature in the test room was constant). Then the necessary characteristics (torque, power, temperature) were recorded. At the second stage the axle was filled with modified oil and torque, power and 
temperature recorded every $200 \mathrm{~km}$ of conditional run. The rotation speed of the motor shaft between the measurements was selected corresponding to the vehicle speed of 50 $\mathrm{km} / \mathrm{h}$.

\section{Results and discussion}

As known energy-saving oil additives reduce mechanical losses in the friction units of the construction vehicles, reduce fuel consumption, improve energy efficiency and vehicle life. Reducing friction losses should lead to a decrease in the heat generation and, accordingly, to the friction unit temperature. Therefore, during the research, the temperature in the engine and transmission was measured.

During the tests of energy-saving engine and transmission oils, the improvement of the performance of internal combustion engines was found:

- fuel consumption decreased by $7.2 \%-8.3 \%$;

- the level of acoustic emission decreased by $0.5-9.1 \%$;

- volume fraction of CO decreased by $12.5-24.5 \%$;

- volume fraction of $\mathrm{CH}$ decreased by $12.6-28.0 \%$;

- compression increased - up to $15.3 \%$;

- engine temperature dropped by $10.0-19.8 \%$.

The greatest change operational characteristics of the internal combustion engine compare with the original recorded in the run up to $500 \mathrm{~km}$. Maximum efficiency of additives was at the run by $1500-2000 \mathrm{~km}$. The effectiveness of the additives takes place during the run up to $10000 \mathrm{~km}$. Energy-saving oils simplified the engine starting of the construction vehicles in negative temperatures conditions of the environment.

The study of additives to transmission oils was carried out at the experimental bench for testing the back axle of the KAMAZ truck. The back axle is the final element of the transmission, perceives significant loads, and its performance can significantly affect the characteristics of the full transmission. Operation of transmissions, especially in the running of vehicles, has variable speed, so a study was conducted on the dependence of the efficiency of the concentrate of additives from the rotational speed.

Efficiency is a main parameter of mechanical transmission. It depends from many factors. The quality and parameters of the using oil has significantly influence to the efficiency of the mechanical transmission. In addition to efficiency, transmission oil has also influence to the temperature load of the mechanical elements.

Thus, comparative tests of the back axle with standard and modified oil in the same operating conditions need to evaluate of energy-saving additives to transmission performance. Also the possibility of the effect accumulation of modified oil during the work of the back axle mechanisms from the conditional mileage of the truck took into account.

The torque values on the shaft were $\mathrm{M} 1=60.4 \mathrm{Nm}$ (power $\mathrm{N}=10 \mathrm{~kW}$ ), M2 $=80 \mathrm{Nm}$ (power $\mathrm{N}=13 \mathrm{~kW}$ ) at $\mathrm{n}=1200 \mathrm{rpm}$ for a axle with standard oil at the tests with two load modes. The relative change of the axle efficiency depending from the run in the tests with 2\% modified energy-saving additives PMT transmission oil, shown in Figure 1. It shows that a small run - up to $300 \mathrm{~km}$, the modified transmission oil slightly reduces the transmission efficiency. This is because for formation of surface friction tribalenergy film needs some time of the transmission operation. After the surface film has been formed (run about $400 \mathrm{~km}$ ) and started to grow, the transmission oil acquires energy-saving properties and there is an increase in the efficiency of the transmission. The relative change in efficiency of oil modified 2\% energy-saving additives PMT for loading mode M1 was $12 \%$ and for the mode M $2-2 \%$. This reason of the axle efficiency changes under different loads can be explained by the values of the power transmitted through the transmission. Loads 
selected during the tests correspond to partial operating modes, which means that the part of losses that determine the efficiency of the axle (for example, in bearing assemblies or in gear pairs) can differ significantly. Therefore, the effect of additives can be different in different modes of operation.

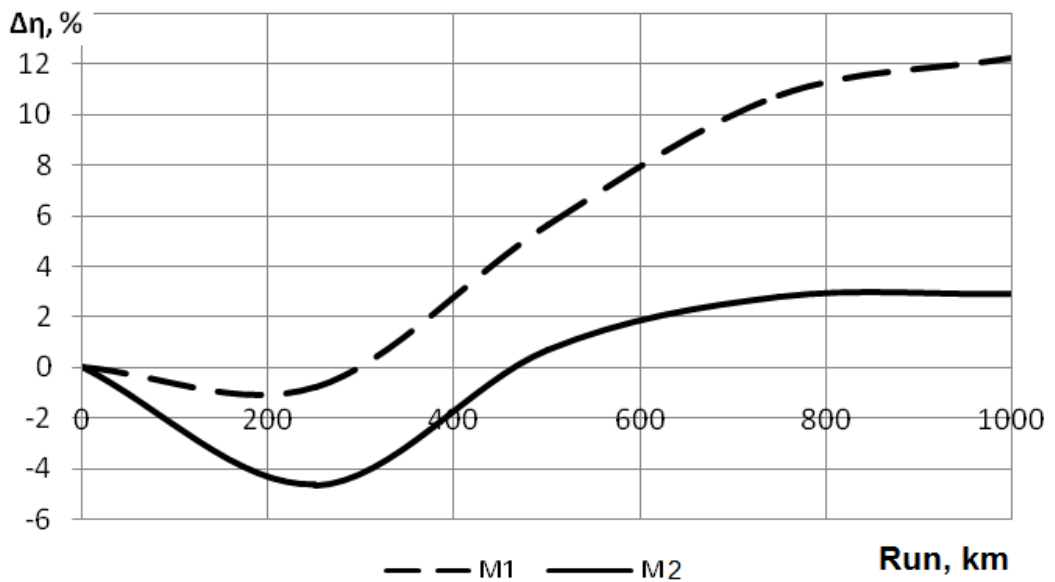

Fig. 1. The relative changing in the efficiency of the axle depending from the run with oil modified by $2 \%$ energy-saving additives PMT at two fixed loads.

The relative changing in the efficiency of the axle depending from the run shown in Figure 2. Test gear oil was modified by $2 \%$ of advanced energy-saving additives NanoPMT. The maximum relative increasing in efficiency was about $12 \%$ for the M1 mode, and about $7 \%$ for the M2 mode. Such type of the efficiency changing is probably due to the work process of additives on the partial loading modes (reduced the loses which have different parts in the general axle efficiency).

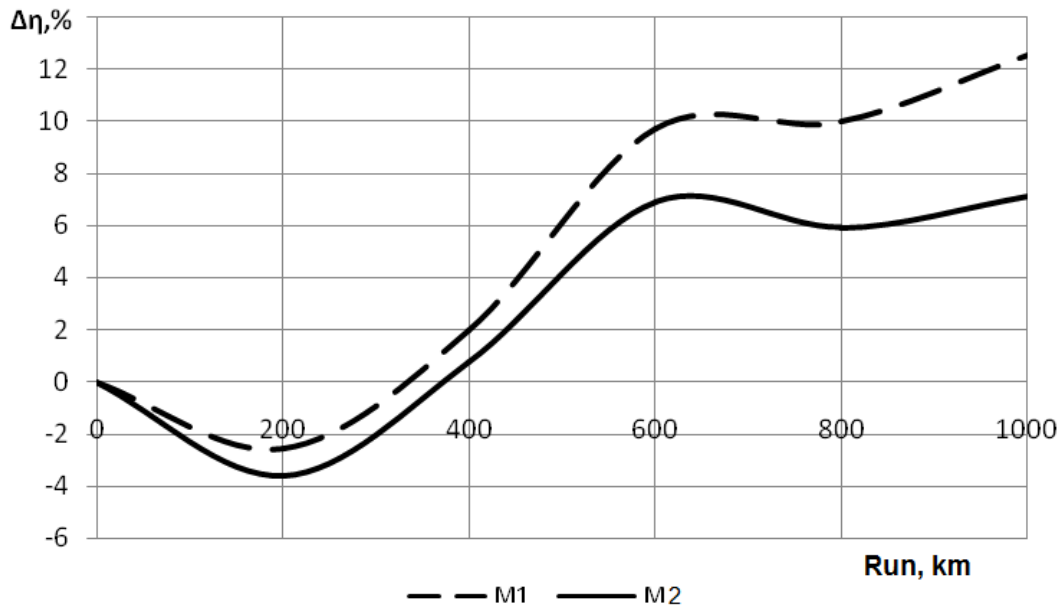

Fig. 2. Relative changing in the efficiency of the axle depending from the run with oil modified by $2 \%$ energy-saving NanoPMT additive at two fixed loads.

The temperature change in the points of the axle hull depending from the run was investigated. The following points were chosen as characteristic: the hull of the center differential (N1), the location of the bearing of the second stage of the main transmission (N2), the axle housing (N3), the bearing units of the hubs (N4, N5). 
The value of temperature changes in the characteristic points of the axle depending from the run are shown in Figures 3, 4. Figure 3 shows that the temperature at the characteristic points of the axle decreases towards the end of the control run. The biggest decrease in temperature $\left(\right.$ at $\left.5{ }^{\circ} \mathrm{C}\right)$ is observed on the hull of the center differential and on the housing of the axle. The temperature in the locations of the bearing units is not significantly reduced. Figure 4 shows that the temperature in the characteristic points of the axle during the tests has not changed.

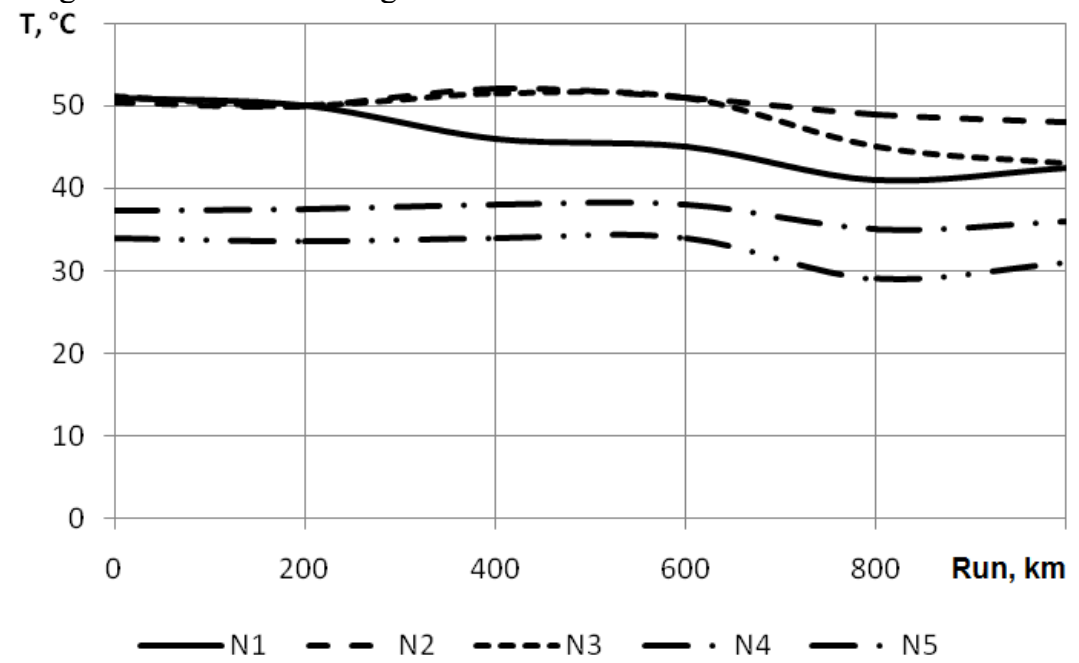

Fig. 3. Temperature change at the characteristic points of the axle with oil modified with $2 \%$ energysaving additive PMT.

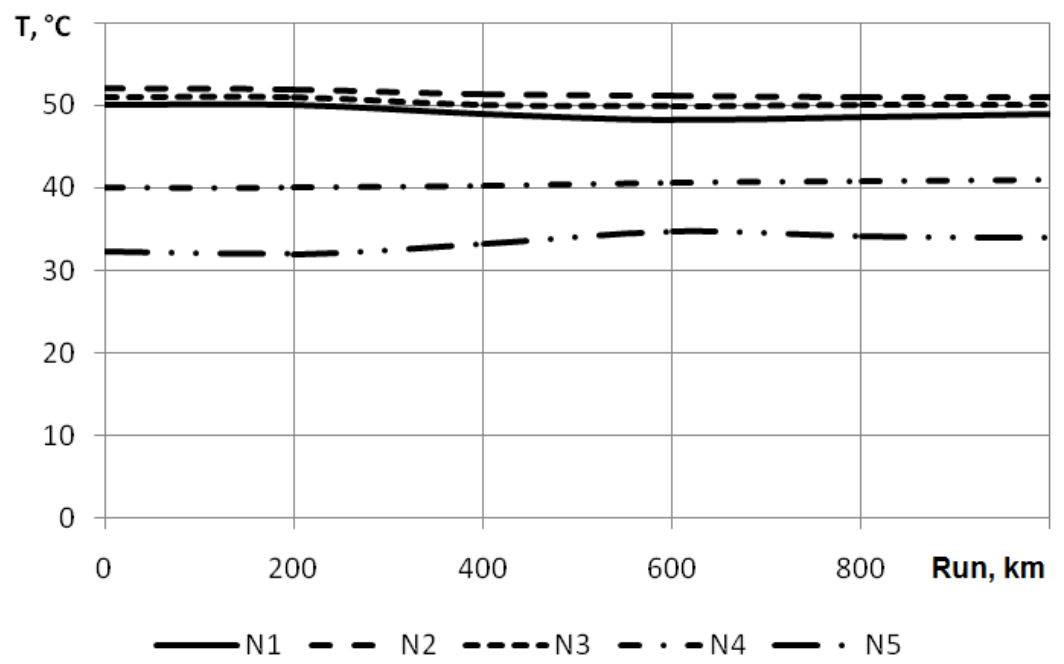

Fig. 4. The temperature changes in characteristic points of the axle with oil modified by $2 \%$ additive NanoPMT.

Thus oil which modified with $2 \%$ energy-saving PMT additive shows the most high efficiency. The oil, modified energy-saving additive PMT decreased level of acoustic emission by $1.8-5.5 \%$, decreased the transmission temperature by $7.3-10.4 \%$ in the course of full-scale tests. 
When using oil, the modified of energy-saving additive nanoPMT the level of acoustic emission decreased by $0.4-4.2 \%$, the transmission temperature decreased by $2.4-5.0 \%$.

According to the results of extended full-scale tests, energy-saving properties of transmission oil SAE 85W90 (TAD-17I) modified by energy-saving additive PMT (2\%) are confirmed. This energy-saving oil is recommended for use in the truck transmissions.

\section{Summary}

The results show the using of energy-saving additives of oils for engine and transmission reduces fuel consumption and increases the truck efficiency.

It was found that developed additives leads to an improvement in the performance of engines in vehicle: the fuel consumption decreased by $7.2 \%-8.3 \%$; the level of acoustic emission decreased by $0.5-9.1 \%$; the CO volume fraction of decreased by $12.5-24.5 \%$; the $\mathrm{CH}$ volume fraction decreased by 12.6 - $28.0 \%$; the compression increasing - up to $15.3 \%$; the engine temperature dropped by $10.0-19.8 \%$.

Tests of energy-saving transmission additives have shown the efficiency of transmissions in the initial period (run $-200-500 \mathrm{~km}$ ) is reduced by $2 \%$ but then increased to $12 \%$ compared to tests on the original transmission oil. The maximum effect was achieved after $1000-2000 \mathrm{~km}$ of the truck run. Along with the increasing in the efficiency of the transmission, the temperature at the characteristic points of the axle are dropped up to $5^{\circ} \mathrm{C}$. The obtained effects are explained by the reduction of friction losses when energysaving additives used in oil.

This work was supported by the grant of Russian scientific Foundation (project No. 1819-00292).

\section{References}

1. U. Schwarz, Science, 348, 40 (2015)

2. A. Ponomarenko, A. Burlov, M. Boiko, T. Shiryaeva, J. of Fric. and Wear, 36, 15 (2015)

3. A. Ponomarenko, M. Boiko, A. Burlov, SGEM, 6, 235 (2015)

4. A. Ponomarenko, V. Dudnik, N. Afanasieva, M. Boiko, MATEC, 133, 01005 (2017)

5. A. Ponomarenko, M. Boiko, A. Kalmykova, T. Boiko, T. Shiryaeva, A. Burlov, J. of Fric. and Wear, 37, 435 (2016) 